\title{
Contrast sensitivity measurement in evaluations of visual symptoms caused by exposure to triethylamine
}

\author{
Pekka Järvinen, Lea Hyvärinen
}

\begin{abstract}
Objectives-To determine whether blurred vision caused by exposure to triethylamine (TEA) can be detected by the measurement of contrast sensitivity. Methods-41 cold box core makers of three foundries and 82 control workers were examined. A detailed ocular and medical history was obtained from the subjects. The contrast sensitivity of the core makers was measured on Monday and Friday of the same week both before and immediately after work and also on a third day, when air samples of TEA were collected. Contrast sensitivity and visual acuity were measured by optotype figures at full contrast, $2.5 \%$ contrast, and $0.6 \%$ contrast. The changes in contrast sensitivity were used for the analysis. The results of binocular vision and the results of the dominant eye were analysed. Urine specimens for the analysis of TEA were collected on every occasion when contrast sensitivity was measured.
\end{abstract}

Results $-78 \%$ of the core makers had had symptoms of blurred vision, and $31 \%$ had had trouble driving or working. The breathing zone eight hour time weighted average TEA concentrations were $0.3-60$ $\mathrm{mg} / \mathrm{m}^{3}$. The mean urinary TEA concentration after the shift was $35 \mathrm{mmol} / \mathrm{mol}$ creatinine. Continuous monitoring showed high peaks of TEA leakage at a core making machine. Changes in binocular visual acuity did not differ between the exposed and unexposed workers. The contrast sensitivity of the core makers decreased significantly at both $2.5 \%$ and $0.6 \%$ contrast during the working day. In the binocular measurements at $2.5 \%$ contrast, sensitivity decreased in $49 \%$ of the core makers and $21 \%$ of the controls $(\mathbf{P}=0.002)$.

Conclusions-The blurred vision caused by exposure to TEA can be documented by measuring contrast sensitivity. The mechanism by which TEA produces symptoms remains an issue of further study.

(Occup Environ Med 1997;54:483-486)

Keywords: triethylamine; contrast sensitivity; visual symptoms

Amines are widely used as catalysts in a reaction between resins and isocyanates. In foundries this reaction is used as a binder in core sand during the cold box core making process. In this process triethylamine (TEA) is used in a vapour phase. This contrasts with most other processes, in which amines are combined with resins. Because it is a vapour, TEA is liberated to ambient air in an amount that can produce symptoms. The most important symptoms are blurred, hazy, or foggy vision, although headache may also occur. ${ }^{1}$ Almost every core maker (95\%) has at some time perceived symptoms of blurred vision. ${ }^{2}$ It has been difficult to measure the blurring of vision by ordinary visual tests. Reilly et al measured the visual acuity of 11 core makers and found no changes between morning measurements and measurements after work when the concentration of TEA was <0.33-20.3 $\mathrm{mg} / \mathrm{m}^{3} .^{2}$ Åkesson et al measured a decrease in visual acuity after four hours of experimental exposure to TEA in a concentration of 48 $\mathrm{mg} / \mathrm{m}^{3}{ }^{3}$ In a study of polyurethane foam workers, Åkesson et al found no changes in visual acuity when the TEA concentration was 1-24 $\mathrm{mg} / \mathrm{m}^{3}$. $^{4}$

The possible cause of the symptoms remained undisclosed. Corneal oedema has been suggested as the main mechanism of the blurred vision. Åkesson et al measured the thickening of the corneal epithelium with an optic Haag-Streit pachymeter. ${ }^{3}$ However, a recent study made by an ultrasonic pachymeter showed no changes in corneal thickness. ${ }^{2}$ The authors recommended further studies of the issue by contrast sensitivity measurement, which has been shown to depict visual impairment in several clinical conditions. ${ }^{5}$ Contrast sensitivity measurements have recently been used in an evaluation of neural disturbances caused by solvent intoxication. Mergler et al studied 54 former electronic assembly workers who had been exposed to organic solvents. ${ }^{6}$ They found a decrease in contrast sensitivity compared with controls, but there were no changes in visual acuity. Campagna et al studied 128 workers exposed to styrene and found that contrast sensitivity was inversely related to the concentration of mandelic acid in urine. ${ }^{7}$ Donoghue et al studied the contrast sensitivity of patients with encephalopathy induced by organic solvents and found abnormal results for six of the 16 subjects. ${ }^{8}$

The objective of this study was to measure whether the blurred vision caused by exposure to TEA can be detected by contrast sensitivity measurements, and to assess the value of the 
Table 1 Triethylamine (TEA) concentration after the shift in urine of core makers

\begin{tabular}{|c|c|c|c|c|}
\hline \multirow[b]{2}{*}{ Foundry } & \multirow{2}{*}{$\begin{array}{l}\text { Core makers } \\
n\end{array}$} & \multirow{2}{*}{$\begin{array}{l}\text { Measurements } \\
n\end{array}$} & \multicolumn{2}{|c|}{$\begin{array}{l}\text { TEA concentration } \\
\text { (mmol/mol creatinine) }\end{array}$} \\
\hline & & & Mean & Median (range) \\
\hline 1 & 17 & 41 & 16 & $11(0.4-72)$ \\
\hline 2 & 9 & 23 & 42 & $37(7-129)$ \\
\hline 3 & 9 & 25 & 60 & $49(17-171)$ \\
\hline Total & 35 & 89 & 35 & $25(0.4-171)$ \\
\hline
\end{tabular}

contrast sensitivity examination in evaluations of toxic symptoms of the visual system.

\section{Materials and methods \\ DESIGN OF THE STUDY}

All workers making cold box cores in three foundries were examined. Two controls were selected for each core maker. One of them did other foundry work that was not prone to exposure to TEA and the other did industrial assembly work without exposure to chemicals or dust. The groups were matched by sex and age. Participation was voluntary, but all the workers agreed to participate. Written informed consent was obtained from each participant.

Contrast sensitivity was examined on Monday and Friday of the same week in the morning before work and in the afternoon immediately after work. Also the contrast sensitivity of the core makers was measured on another day when the measurement of the concentration of TEA in the air was carried out. Personal breathing zone and stationary air TEA samples were collected in each foundry. Also, continuous monitoring by an infrared analyser was carried out in the foundries. All the people working on the days of the measurements took part in the study.

The TEA concentration of urine specimens was used as an indicator of exposure to TEA. Urine samples were collected from the core makers on every occasion that the contrast sensitivity was measured. Random urine samples were collected from the controls to verify that they were unexposed to TEA.

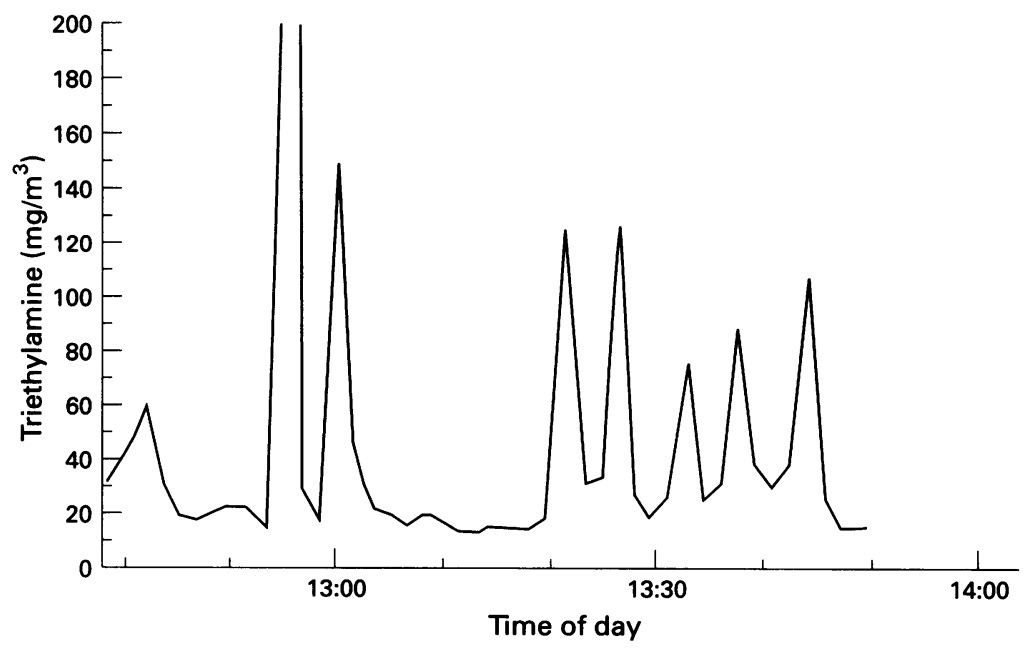

Figure 1 Concentration of triethylamine in the ambient air of a core making machine in foundry 2 during the continuous measurement by an infrared analyser. The mean (maximum) concentration of TEA was 46 (486) $\mathrm{mg} / \mathrm{m}^{3}$.
VISUAL ACUITY AND CONTRAST SENSITIVITY

TESTING

Visual acuity and contrast sensitivity were tested with test charts based on the numerals 5 , 6,8 , and 9 with five numbers in each row of the charts in an $0.1 \mathrm{log}$ scale at full contrast, $2.5 \%$ contrast, and $0.6 \%$ contrast (Precision Vision, Villa Park, Illinois, USA). The chart was read from a distance of $4.0 \mathrm{~m}$. Visual acuity was defined at each level as three or more correct responses out of five.

Only subjects with binocular visual acuity of 1.2 or better and monocular visual acuity of 1.0 or better were accepted for the contrast sensitivity measurements. Six of the core makers and eight of the controls did not meet these requirements. No subjects were accepted with contact lenses. One core maker and one control wore contact lenses.

The measurements were conducted by occupational health nurses. Contrast sensitivity was examined in the morning before work and in the afternoon immediately after work. The change between the morning and afternoon visual acuity values was used in the statistical analysis. The results obtained from the binocular measurements and from the measurements of the dominant eye were included in the statistical analysis.

The examinations were conducted in five separate places, under typical room illumination with no daylight and no sources of glare. Contrast sensitivity charts were illuminated by Philips TLD 36W/33 fluorescent lamps with asymmetric reflectors. Luminance was measured at six points of the white surface of the chart by a Minolta luminance metre and adjusted to be between 120 and 150 candelas per metre squared $\left(\mathrm{cd} / \mathrm{m}^{2}\right)$.

HEALTH QUESTIONNAIRE AND OCULAR SYMPTOMS The ophthalmological and general health status of the subjects was obtained in a face to face interview with the occupational health nurses. The interview was based on a questionnaire. The subjects were asked about previous ocular diseases and accidents and their use of spectacles and contact lenses. They were also asked about previous and present medications as well as systemic diseases.

The subjects were asked to describe any eye symptoms that had occurred during the previous 12 months. They were also asked if the symptoms occurred during their work, maintenance activities, or breaks in their work. Finally they were asked if their symptoms were the same as those previously described as typical.'

EXPOSURE

In the assessment of exposure to TEA urine and air samples were analysed by gas chromatography according to principals described by Åkesson et al. ${ }^{9}$

\section{STATISTICAL ANALYSES}

Medians of the visual acuity values were tested by the median two sample test. Changes in visual acuity were tested by a $\chi^{2}$ for trend test. Changes in visual acuity in relation to the TEA 
concentration in urine were tested by analysis of variance (ANOVA).

\section{Results}

Each group consisted of 41 people, 37 of whom took part in the entire study. Three people changed jobs soon after the symptom questionnaire was filled out. The total number of people who took part in the study was 123 . Of the 41 core makers 32 were men and nine were women, whereas 64 of the controls were men and 18 were women. The mean (range) age of the core makers was 34.1 (18-60) years, and that of the controls was 34.7 (19-59) years. The mean (range) working time of the core makers was three years and seven months (1 month-19 years).

Both control groups were similar in general health status, ocular history, eye symptoms, changes in visual acuity, and contrast sensitivity. Consequently, the results of the two groups were combined.

The core makers and the controls did not differ for general health, ocular diseases, and ocular accident history although the controls had slightly more allergic eye symptoms. They

Table 2 Median visual acuity values at different contrasts on Monday and Friday afternoon

\begin{tabular}{|c|c|c|}
\hline \multirow[b]{2}{*}{ Day and contrast used } & Binocular vision & Dominant eye \\
\hline & Median (0.25-0.75 quartiles) & Median (0.25-0.75 quartiles) \\
\hline \multicolumn{3}{|l|}{ Monday afternoon: $\S$} \\
\hline \multicolumn{3}{|l|}{ High contrast: } \\
\hline Core makers & $1.25(1.25-1.6)$ & $1.25(1.0-1.425)$ \\
\hline Controls & $1.6 \quad(1.25-1.6)$ & $1.25(1.25-1.6)^{\star}$ \\
\hline \multicolumn{3}{|l|}{$2.5 \%$ contrast: } \\
\hline Core makers & $0.625(0.5-0.63)$ & $0.5 \quad(0.4-0.5)$ \\
\hline Controls & $0.63(0.5-0.63)$ & $0.5 \quad(0.4-0.63)$ \\
\hline \multicolumn{3}{|l|}{$0.6 \%$ contrast: } \\
\hline Core makers & $0.32(0.25-0.32)$ & $0.25(0.16-0.285)$ \\
\hline Controls & $0.32(0.25-0.4)$ & $0.25(0.16-0.32)$ \\
\hline \multicolumn{3}{|l|}{ Friday afternoon:I } \\
\hline \multicolumn{3}{|l|}{ High contrast: } \\
\hline Core makers & $1.6 \quad(1.25-1.6)$ & $1.6(1.25-1.6)$ \\
\hline Controls & $1.6 \quad(1.25-1.6)$ & $1.6(1.25-1.6)$ \\
\hline \multicolumn{3}{|l|}{$2.5 \%$ contrast: } \\
\hline Core makers & $0.63(0.5-0.63)$ & $0.5 \quad(0.4-0.5)$ \\
\hline Controls & $0.63(0.5-0.8)$ & $0.5(0.5-0.63) \dagger$ \\
\hline \multicolumn{3}{|l|}{$0.6 \%$ contrast: } \\
\hline Core makers & $0.32(0.25-0.4)$ & $0.25(0.16-0.32)$ \\
\hline Controls & $0.32(0.32-0.4)$ & $0.32(0.2-0.32) \ddagger$ \\
\hline
\end{tabular}

$\star \mathrm{P}=0.03 ;+\mathrm{P}=0.04 ; \ddagger \mathrm{P}=0.01$.

$\oint$ Number of core makers 32, controls 67 . $\uparrow$ Number of core makers 29, controls 66 .

Table 3 Differences in visual acuity between the morning and afternoon measurements

\begin{tabular}{|c|c|c|c|c|}
\hline \multirow[b]{2}{*}{$\begin{array}{l}\text { Contrast } \\
\text { Degree of change }\end{array}$} & \multicolumn{2}{|c|}{ Binocular vision } & \multicolumn{2}{|l|}{ Dominant eye } \\
\hline & $\begin{array}{l}\text { Core makers } \\
n(\%)\end{array}$ & $\begin{array}{l}\text { Controls } \\
n(\%)\end{array}$ & $\begin{array}{l}\text { Core makers } \\
n(\%)\end{array}$ & $\begin{array}{l}\text { Controls } \\
n(\%)\end{array}$ \\
\hline \multicolumn{5}{|l|}{ High contrast: } \\
\hline Improved & $5(15)$ & $15(22)$ & $5(15)$ & $20(29)$ \\
\hline Unchanged & $18(55)$ & $33(49)$ & $13(39)$ & $33(49)$ \\
\hline Deteriorated & $10(30)$ & $20(29)$ & $15(46)$ & $15(22)^{\star}$ \\
\hline $\begin{array}{l}2.5 \% \text { contrast: } \\
\text { Improved }\end{array}$ & $4(12)$ & $24(35)$ & $7(21)$ & $21(31)$ \\
\hline Unchanged & $13(39)$ & $30(44)$ & $9(27)$ & $32(47)$ \\
\hline Deteriorated & $16(49)$ & $14(21) \dagger$ & $17(52)$ & $15(22) \ddagger$ \\
\hline \multicolumn{5}{|l|}{$0.6 \%$ contrast: } \\
\hline Improved & $5(15)$ & $26(38)$ & $7(21)$ & $26(38)$ \\
\hline Unchanged & $12(36)$ & $19(28)$ & $7(21)$ & $23(34)$ \\
\hline Deteriorated & $16(49)$ & $23(34)^{5}$ & $19(58)$ & $19(28)$ \\
\hline
\end{tabular}

$\star P=0.02 ; \uparrow P=0.002 ; \ddagger P=0.02 ; \bigotimes P=0.03 ; \uparrow P=0.01$. Number of core makers 33 , controls 68 . All measurements of a person are summarised: core makers Monday and Friday measurements, and measurements on the day when TEA concentration in the air was measured; controls Monday and Friday measurements.
Table 4 Changes in visual acuity between the morning and afternoon measurements in relation to symptoms of blurred vision

\begin{tabular}{llll}
\hline & $\begin{array}{l}\text { Core makers } \\
\text { with symptoms } \\
n(\%)\end{array}$ & $\begin{array}{l}\text { Core makers } \\
\text { without } \\
\text { symptoms } \\
n(\%)\end{array}$ & $\begin{array}{l}\text { Controls } \\
n(\%)\end{array}$ \\
Degree of change & $1(17)$ & $6(22)$ & $21(31)$ \\
Improved & $1(17)$ & $8(30)$ & $32(47)$ \\
Unchanged & $4(66)$ & $13(48)$ & $15(22)^{\star}$ \\
Deteriorated & 6 & 27 & 68 \\
Total & 6 &
\end{tabular}

$\star \mathrm{P}=0.046$ between core makers without symptoms and controls. Dominant eye at $2.5 \%$ contrast; all the measurements of a person are summarised.

had similar use of spectacles and eye medication.

EXPOSURE

The breathing zone eight hour time weighted average ( $8 \mathrm{~h}$ TWA) concentration of TEA was $0.3-60 \mathrm{mg} / \mathrm{m}^{3}$. The median $8 \mathrm{~h}$ TWA concentrations in the three foundries were $0.9,4.7$, and $14 \mathrm{mg} / \mathrm{m}^{3}$. Continuous measurements showed high peaks of TEA leaking from the system, especially when the core box was rinsed (fig 1). The urinary TEA concentrations of the core makers varied between 0.4 and 171 $\mathrm{mmol} / \mathrm{mol}$ creatinine. The mean urinary TEA concentration was $35 \mathrm{mmol} / \mathrm{mol}$ creatinine (table 1). There was no TEA in the urine samples of the controls.

\section{SYMPTOMS}

Seventy eight per cent (32/41) of the core makers and $6 \%(5 / 80)$ of the controls had sometimes had visual symptoms $(P=0.001)$. Of the core makers, $78 \%$ (25/32) reported symptoms during normal production and $22 \%$ (7/32) listed symptoms only during maintenance or breaks in their jobs. Thirty one core makers (97\%) had foggy, blurred vision, 16 (50\%) saw halos around light sources, 14 (44\%) saw hazy contours, 12 (37\%) felt tearing, 11 (34\%) had difficulty reading, 10 (31\%) had difficulties in driving and working $10(31 \%)$ felt glare, seven $(22 \%)$ experienced photophobia and, five (16\%) had blue vision. One control reported blurry vision $(P=0.001)$. None of the controls reported any of the other symptoms.

\section{VISUAL ACUITY AND CONTRAST SENSITIVITY} TESTING

Table 2 shows the median visual acuities for each contrast level. The results did not differ between the core makers and the controls in the morning measurements. In the afternoon measurements there were significant decreases in three of the six measurements of the dominant eye. Table 3 shows the differences in visual acuity between the morning and afternoon measurements. The contrast sensitivity of the core makers decreased significantly at both $2.5 \%$ and $0.6 \%$ contrast during the working day. In the binocular measurements at $2.5 \%$ contrast, contrast sensitivity decreased among $49 \%$ of the core makers and $21 \%$ of the controls $(P=0.002)$. Six people reported blurred vision during 10 measurements in the course of the study (table 4 ). 


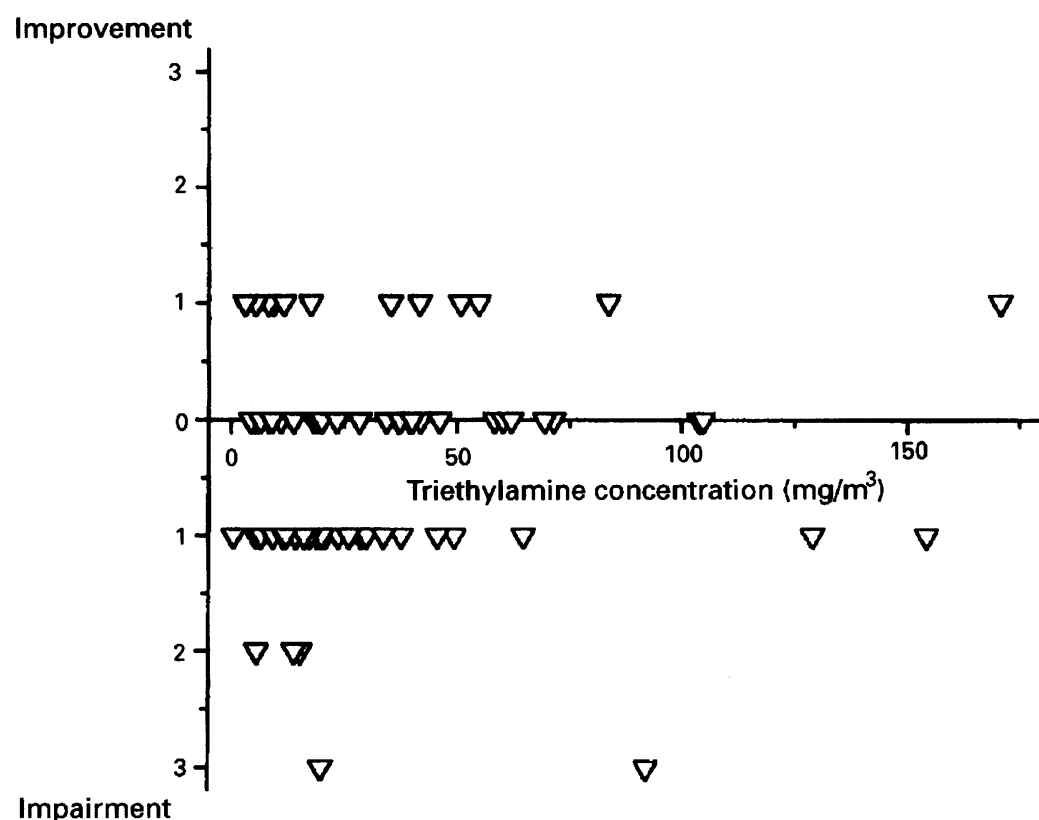

Figure 2 Differences between the morning and afternoon contrast sensitivity of the dominant eye at $2.5 \%$ contrast in relation to the urinary triethylamine (TEA) concentration (mmol/mol creatinine). Number of measurements $=74$.

Figure 2 shows the changes in the visual acuity of the dominant eye between the morning and afternoon measurements in relation to the urinary TEA concentrations. There was no significant relation between the differences in contrast sensitivity and the urinary TEA concentration.

\section{Discussion}

Contrast sensitivity measurement has not yet been used to study toxic effects on the anterior part of the eye. During the measurement of contrast sensitivity the subject must not have uncorrected refractive errors. Contact lenses interfere with the measurements because they affect the corneal epithelium, and influence contrast sensitivity, depending on the cleanliness and fit of the lenses. ${ }^{10}$

Blurred vision was common among core makers. Visual disturbances interfered with working, driving, and reading of almost one third of the subjects. Although there was no evidence of permanent damage to the eyes or visual pathway, the problem is notable from the personal and community point of view.

The median visual acuity values of the groups were equal in most measurements, but the $0.25-0.75$ quartiles differed in some measurements. Apparently the effect of exposure to TEA is not sufficient to become evident in comparisons of the medians of visual acuity. Therefore, the difference between the morning and afternoon measurements was used for the analysis. The differences in binocular visual acuity at high contrast were equal among the core makers and the controls, but at $2.5 \%$ and $0.6 \%$ contrast the groups differed significantly both in the binocular measurements and in the measurements of the dominant eye. The subjects considered the contrast sensitivity measurements at $0.6 \%$ contrast to be difficult, and the differences were not as evident as at $2.5 \%$ contrast. The results of the dominant eye at high contrast were close to the results at $2.5 \%$ and $0.6 \%$ contrast.

The number of the core makers with symptoms of blurred vision during the measurements was too small for statistical analyses, but four people out of six had deteriorated vision at $2.5 \%$ contrast. The changes in visual acuity at $2.5 \%$ contrast differed significantly between core makers without symptoms and the controls. This suggests that core makers had a decrease in contrast sensitivity more often than they had symptoms.

It is not known if the pulsating nature of exposure to TEA is important to the mechanism of blurred vision. Figure 1 shows that the peaks of TEA leakage can be remarkably high, although the method of continuous measurement does not provide an exact measurement of the exposure.

The measurements did not show a doseresponse relation between exposure to TEA and changes in contrast sensitivity. This is probably because of individual variation in perceiving the symptoms. Also the blurring of vision may be caused by an on-off, rather than a dose-response phenomena.

The results suggest that the symptoms of blurred vision during exposure to TEA can be documented by measurement of contrast sensitivity. The measurement of visual acuity at low contrast may show deterioration in vision when high contrast tests fail to measure subjective visual symptoms.

\section{Conclusions}

Blurred vision during exposure to TEA can be documented by contrast sensitivity measurements. Contrast sensitivity testing proved to be of value in measuring toxic effects on the eye. The results of contrast sensitivity measurements in this study did not show the mechanism causing the symptoms. Therefore, the mechanism should be studied with more complex methods of testing contrast sensitivity or new methods of ophthalmological examination of the eye.

The study was supported by the Finnish Work Environment Fund.

1 Albrecht W, Stephenson R. Health hazards of tertiary amine catalysts. Scand F Work Environ Health 1988;14;209-19.

2 Reilly M, Rosenman K, Abrams J, Zhu Z, Tseng C, Hertzberg V, et al. Ocular effects of exposure to triethylamine in the sand core cold box of a foundry. Occup Environ Med the sand core cold

3 Ákesson B, Floren I, Skerfving S. Visual disturbances after experimental human exposure to triethylamine. Br $\mathcal{F}$ Ind experimental human

4 Åkesson B, Bengtsson M, Floren I. Visual disturbances after Aksson B, Bengtsson M, Floren I. Visual disturbances after
industrial triethylamine exposure. Int Arch Occup Environ Health 1986;57:297-302.

5 Hyvärinen L. Contrast sensitivity testing in clinical practice. Br f Opththalmol 1995;79:867.

6 Mergler D, Huel G, Bowler R, Frenette B, Cone J. Visual dysfunction among former microelectronics assembly workers. Arch Environ Health 1991;46:326-33.

7 Campagna D, Mergler D, Huel G, Belanger S, Truchon G, Ostiguy $\mathrm{C}$, et al. Visual dysfunction among styrene-exposed workers. Scand $¥$ Work Environ Health 1995;21:382-90.

8 Donoghue M, Dryson E, Wynn-Williams G. Contrast sensitivity in organic- solvent induced chronic toxic encephalopathy. F Occup Environ Health 1995;37:1357-63.

9 Åkesson B, Skerfving S, Mattiasson L. Experimental study on the metabolism of triethylamine in man. $\mathrm{Br} \mathcal{F}$ Ind Med 1988;45:262-8.

10 Bruce A, Brennan N. Corneal pathophysiology with contact lens wear. Surv Ophthalmol 1990;35:25-58. 